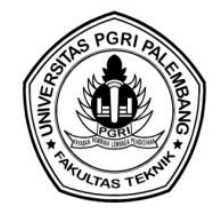

\title{
PENGARUH CAMPURAN SERBUK STYROFOAM DAN BIJI PLASTIK JENIS PVC PADA DAYA DUKUNG TANAH DAN NILAI CBR TANAH DASAR (SUBGRADE) DI RUAS JALAN DESA BATTU WINANGUN KABUPATEN OGAN KOMERING ULU
}

\author{
Ferry Desromi ${ }^{1}$, Yuliantini Eka Putri ${ }^{2 *}$, Endah Kartika Sari ${ }^{3}$, Abdul Rahman ${ }^{4}$ \\ ${ }^{1,2,3}$ Prodi Teknik Sipil, Fakultas Teknik dan Komputer, Universitas Baturaja \\ ${ }^{4}$ Prodi Informatika, Fakultas Teknik dan Komputer, Universitas Baturaja \\ "Corresponding Author, Email : yuliantini6773@gmail.com
}

\begin{abstract}
ABSTRAK
Jalan Desa Batumarta Unit I sampai Desa Battu Winangun Kecamatan Lubuk Raja merupakan jalur lalu lintas yang cukup tinggi penggunanya dan saat ini kondisinya banyak mengalami kerusakan dan permukaan jalan yang tidak rata atau bergelombang. Tujuan penelitian untuk menganalisa pengaruh penambahan campuran serbuk sterofom dan biji plastik sebesar 0\%, 1\%, dan 1,5\% terhadap nilai CBR tanah dasar (subgrade) pada Jalan Desa Batumarta I sampai Desa Battu Winangun Kecamatan Lubuk Raja. Berdasarkan survey dilapangan di 3 titik sampel dan hasil uji di Laboratorium Program Studi Teknik Sipil Universitas Baturaja menunjukkan bahwa pengaruh penambahan serbuk Styrofoam dan biji plastik pada komposisi campuran sebesar 1\% di titik 1 terdapat peningkatan nilai CBR dan DDT yaitu CBR 6,0\%-52 DDT, di titik 3 CBR 5,2 \% - 4,8 DDT, sedangkan di titik 2 CBR 5,9\% - 5,1 DDT, di mana nilai CBR di titik 3 tidak mencapai nilai kualitas CBR yang maksimal. Sehingga disimpulkan bahwa dengan komposisi campuran tanah dasar ditambah $1 \%$ serbuk styrofoam dan biji plastik merupakan formula komposisi campuran yang baik dan dapat mencapai nilai CBR yang stabil terutama di titik 1 dan titik 2. Di mana semakin besar kadar serbuk styrofoam dan biji plastik yang ditambahkan, maka daya dukung tanah akan mengalami penurunan di karenakan serbuk styrofoam dan biji plastik merupakan unsur material bukan pengikat.
\end{abstract}

Kata Kunci : Nilai CBR; DDT; Serbuk Styrofoam; Biji Plastik.

\begin{abstract}
The Batumarta Village Unit I to Battu Winangun Village, Lubuk Raja District is a traffic lane that is quite high in users and currently its condition is experiencing a lot of damage and the road surface is uneven or bumpy. The purpose of the study was to analyze the effect of adding a mixture of sterofom powder and plastic seeds of $0 \%, 1 \%$, and $1.5 \%$ on the CBR value of the subgrade on Jalan Desa Batumarta I to Desa Battu Winangun, Lubuk Raja District. Based on a field survey at 3 sample points and test results at the Laboratory of the Civil Engineering Study Program, Baturaja University, it shows that the effect of adding Styrofoam powder and plastic seeds to the composition of the mixture is $1 \%$ at point 1 there is an increase in CBR and DDT values, namely CBR 6.0\% - 52 DDT, at point 3 CBR 5.2\%-4.8 DDT, while at point 2 CBR $5.9 \%$ - 5.1 DDT, where the CBR value at point 3 did not reach the maximum CBR quality value. So it was concluded that the composition of the subgrade mixture plus $1 \%$ styrofoam powder and plastic seeds is a good mix composition formula and can achieve a stable CBR value, especially at point 1 and point 2. Then the carrying capacity of the soil will decrease because styrofoam powder and plastic seeds are non-binding material elements
\end{abstract}

Keywords : Value of CBR; DDT; Styrofoam Powder; Plastic Pellets

\section{PENDAHULUAN}

Jalan merupakan prasarana yang sangat penting di dalam transportasi darat, dimana 
perekonomian suatu daerah sangat tergantung dari transportasi darat berupa jalan. Jalan dapat meningkatkan kegiatan ekonomi di suatu tempat karena menolong orang untuk pergi atau mengirim barang lebih cepat ke suatu tujuan. Dengan adanya jalan, komoditas dapat mengalir ke pasar setempat dan hasil ekonomi dari suatu tempat dapat dijual kepada pasaran di luar wilayah itu. Selain itu, jalan juga mengembangkan ekonomi lalu lintas di sepanjang lintasannya. Desa Batumarta I dan Desa Battu Winangun Kecamatan Lubuk Raja merupakan wilayah desa yang terletak di Kabupaten Ogan Komering Ulu. Dalam kegiatan ekonominya kedua desa ini menggunakan jalan penghubung antar desa, dimana fungsi jalan penghubung ini memberikan dampak kemajuan yang besar untuk daerah tersebut dan merupakan jalur lalu lintas yang cukup tinggi penggunanya. Tetapi saat ini kondisi jalan tersebut banyak mengalami kerusakan, dengan kondisi tanah yang turun sehingga mengganggu kelancaran transportasi. Dengan kondisi tersebut perlu diadakan penelitian untuk mencari alternatif solusi guna meningkatkan kualitas mutu jalan yang baik dan kokoh. Dan salah satu kajiannya yaitu melakukan pengujian nilai CBR dengan menambahkan campuran styrofoam dan biji plastik untuk mengetahui suatu kondisi tanah dasar (subgrade), dimana styrofoam dan plastik merupakan limbah sampah rumah tangga yang dibuang dan tidak dimanfaatkan. Pencampuran serbuk styrofoam dan biji plastik pada tanah dengan persentase campuran yang berbeda dilakukan dengan metode uji laboratorium. Dan hal ini untuk mengetahui pengaruhnya pada daya dukung tanah dan nilai CBR yang terdapat di jalan Desa Batumarta Unit I sampai Desa Battu Winangun. Menurut Verhoef (dalam Watie \& Chandra 2021) tanah sebagai kumpulan dari bagianbagian yang padat dan tidak terikat antara satu dengan yang lain, rongga-rongga diantara material tersebut berisi udara dan air. Jadi tanah meliputi gambut, tanah organik, lempung, lanau, pasir dan kerikil atau campurannya (Norhadi \& Rukmana 2017).

Adapun menurut Bowles (1991) kelompok-kelompok tanah utama pada sistem klasifikasi unified diperlihatkan pada tabel berikut ini :

Tabel 1. Sistem Klasifikasi Tanah unified

\begin{tabular}{lccc}
\hline \multicolumn{1}{c}{ Jenis Tanah } & Simbol & Sub Kelompok & Simbol \\
\hline Kerikil & $\mathrm{G}$ & Gradasi Baik & $\mathrm{W}$ \\
& & Gradasi Buruk & $\mathrm{P}$ \\
Pasir & $\mathrm{S}$ & Berlanau & $\mathrm{M}$ \\
& & Berlempung & $\mathrm{C}$ \\
Lanau & $\mathrm{M}$ & & \\
Lempung & $\mathrm{C}$ & $\mathrm{WL}<50 \%$ & $\mathrm{~L}$ \\
Organik & $\mathrm{O}$ & $\mathrm{WL}>50 \%$ & $\mathrm{H}$ \\
Gambut & $\mathrm{Pt}$ & & \\
\hline
\end{tabular}

Sumber: Bowles, 1991.

Beberapa pendapat para peneliti mengenai definisi dari tanah lempung, yaitu:

1. Tanah lempung merupakan agregat partikel-partikel berukuran mikroskopik dan submikroskopik yang berasal dari pembusukan unsur-unsur kimiawi penyusun batuan. Tanah lempung bersifat sangat keras dalam keadaan kering dan plastis dalam selang kadar air sedang. Pada keadaan air lebih tinggi, lempung bersifat lengket (kohesif) dan sangat lunak (Terzaghi dalam Purwanto et al 2020), 
2. Tanah lempung merupakan deposit yang mempunyai partikel berukuran lebih kecil atau sama dengan 0,002 $\mathrm{mm}$ dalam jumlah lebih dari 50\% (Bowles dalam Susmarani 2012),

3. Tanah lempung terdiri dari partikel mikroskopis dan submikroskopis yang berbentuk lempengan-lempengan pipih dan merupakan partikel dari mika, mineral lempung, dan mineral lain yang sangat halus lain (Das dalam Rustam et al 2020);

4. Tanah lempung terdiri dari butir-butir yang sangat kecil $(<0,002 \mathrm{~mm})$ dan menunjukkan sifat-sifat plastisitas dan kohesi. Kohesi menunjukkan kenyataan bahwa bagian-bagian itu melekat satu sama lainnya, sedangkan plastisitas adalah sifat yang memungkinkan bentuk bahan itu diubah-ubah tanpa perubahan isi atau tanpa kembali ke bentuk aslinya, dan tanpa terjadi retakan-retakan atau terpecah-pecah (Das dalam Gunarti 2013);

5. Tanah lempung memiliki ukuran butiran halus $>0,002 \mathrm{~mm}$, permeabilitas rendah, kenaikan air kapiler tinggi, bersifat sangat kohesif, kadar kembang susut yang tinggi dan poses konsolidasi lambat (Hardiyatmo dalam Rustam 2018), ;

6. Warna tanah pada tanah lempung tidak dipengaruhi oleh unsur kimia yang terkandung didalamnya, karena tidak adanya perbedaan yang dominan dimana kesemuanya hanya dipengaruhi oleh unsur natrium saja yang paling mendominasi. Semakin tinggi plastisitas, grafik yang dihasilkan pada masing-masing unsur kimia belum tentu sama. Hal ini disebabkan karena unsur-unsur warna tanah dipengaruhi oelah nilai Liquid Limid (LL) yang berbeda (Marindo dalam Setiawan, et al 2016), ;

7. Sifat-sifat tanah lempung adalah (1) Ukuran butir halus, kurang dari 0,002 mm, (2) Permeabilitas rendah (3) Peningkatan air kapiler tinggi (4) Sifat sangat kohesif (5) Tingkat penyusutan dan pertumbuhan yang tinggi (6) proses konsolidasi lambat (Purwanto, et al 2020).

Teknologi stabilisasi tanah dapat dibagi menjadi 4 (empat) macam penggolongan utama, yaitu :

1. Physio - Chemical, pencampuran tanah asli dengan semen, kapur ataupun aspal sebagai bahan pengikat partikel tanah.

2. Granulometric, pencampuran tanah asli dengan tanah lain yang mempunyai sifat dan karakteristik yang lebih baik lalu dipadatkan dengan alat pemadat.

3. Physio - Mechanical, pemadatan langsung dengan alat pemadat maupun aplikasi teknologi seperti cakar ayam, tiang pancang dan geomembran atau geotextile.

4. Electro - Chemical, ionisasi partikel tanah dengan mencampurkan bahan kimia tertentu contohnya TX-300, yang bertujuan untuk merubah sifat-sifat buruk tanah, seperti kembang susut menjadi tanah yang mudah dipadatkan dan stabil secara permanen.

Plastik adalah bahan polimer sintetis yang terbagi menjadi banyak jenis berdasarkan sifat fisis, mekanis, dan kimia. Plastik umumnya ringan, bersifat isolator, dan proses pembuatannya lebih murah dibandingan dengan bentuk kemasan lainnya. Menurut identifikasi jenis plastik yang banyak terdapat di masyarakat banyak berasal dari bahan polyethylene. Polyethylene sendiri dibagi menjadi dua, yaitu High Density Polyethylene 
(HDPE) dan Low Density Polyethylene (LDPE). HDPE banyak digunakan untuk botol minuman, sedangkan LDPE banyak digunakan untuk kantong plastik. Styrofoam yang memiliki nama lain polystyrene, begitu banyak digunakan oleh manusia dalam kehidupannya sehari hari. Begitu Styrofoam diciptakan pun langsung marak digunakan di Indonesia.

Menurut Simanjuntak et al (2017), CBR merupakan suatu perbandingan antara beban percobaan (Test Load) dengan beban standar (Standard Load) dan dinyatakan dalam persentase. Perkerasan jalan harus memenuhi 2 syarat yaitu :

1. Secara keseluruhan perkerasan jalan harus cukup kuat untuk memikul berat kendaraan-kendaraan yang akan memakainya.

2. Permukaan jalan harus dapat menahan gaya gesekan dan keausan dari roda-roda kendaraan, juga terhadap pengaruh air dan hujan

CBR diklasifikasikan seperti tabel berikut :

Tabel 2. Klasifikasi Nilai CBR

\begin{tabular}{ccc}
\hline Nilai CBR & Kualitas Uji & Lapisan \\
\hline $0-3$ & Sangat Buruk & Subgrade \\
$3-7$ & Buruk & Subgrade \\
$7-20$ & Cukup & Subbase \\
$20-50$ & Baik & Base, subbase \\
$>50$ & Sangat Baik & Base, subbase \\
\hline
\end{tabular}

Daya dukung tanah dasar ditetapkan berdasarkan grafik kolerasi. Daya dukung tanah dasar diperoleh dari nilai CBR atau Plate Bearing Test, DCP, dan lain-lain. Korelasi daya dukung tanah dasar dengan CBR subgrade
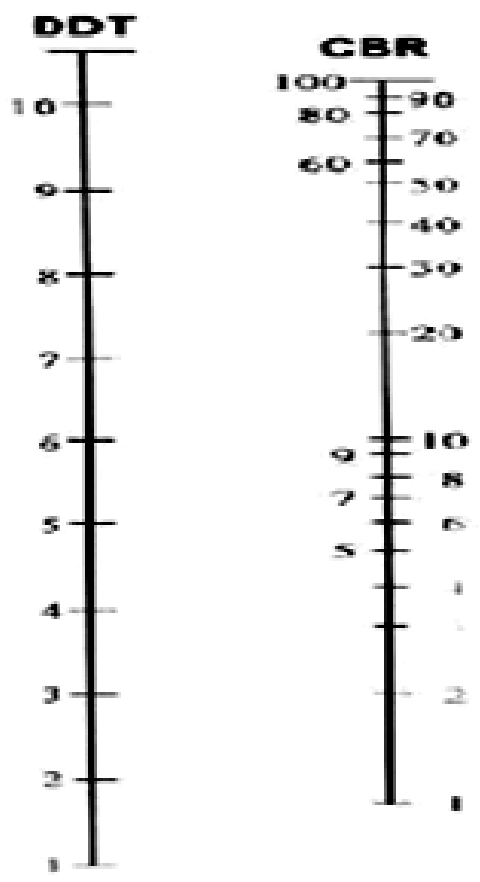

Gambar 1. Diagram Korelasi 


\section{METODE PENELITIAN}

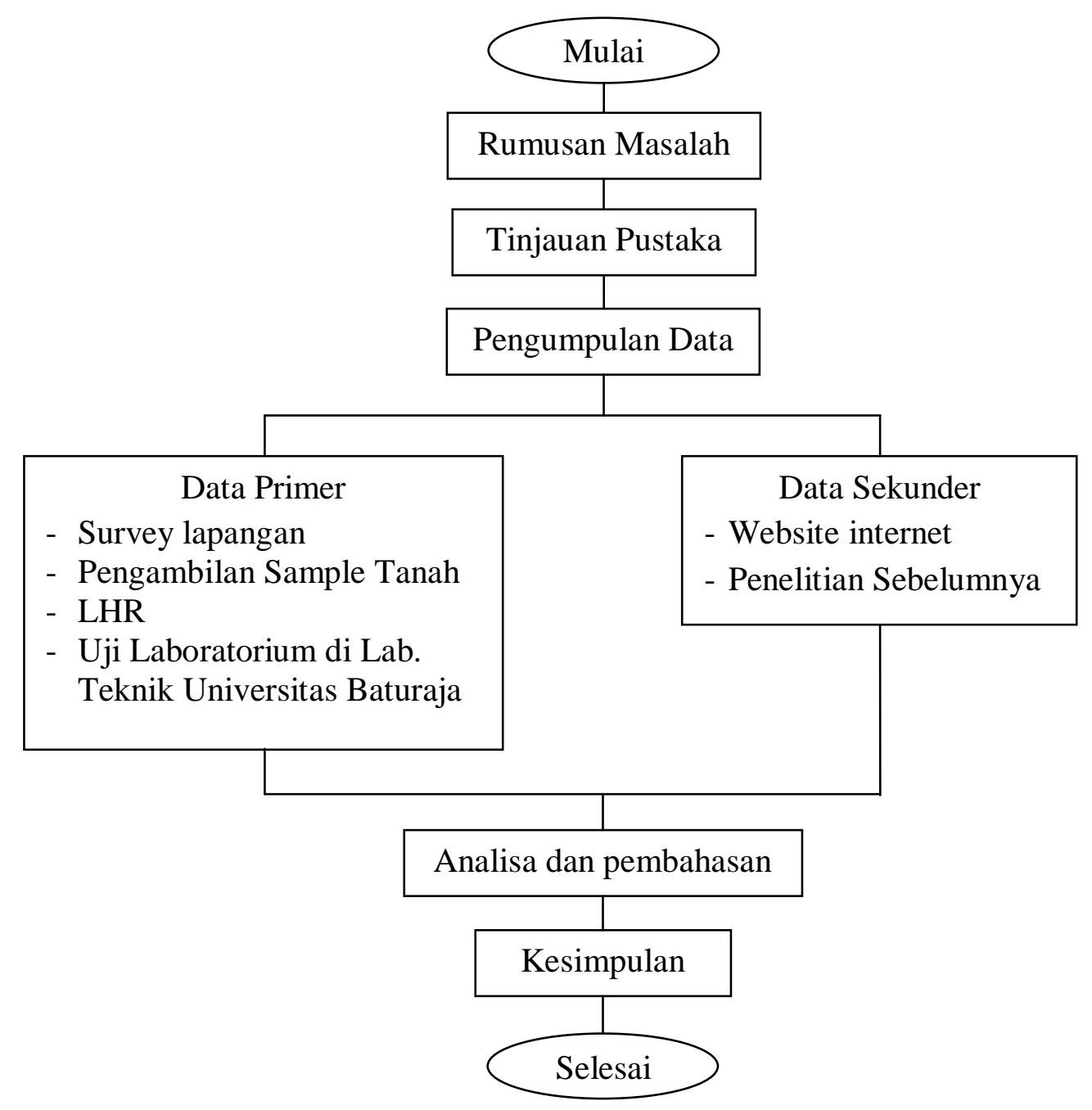

Gambar 2. Bagan Alir Penelitian

Analisa data yang digunakan untuk mendeskrpsikan penelitian meliputi :

1. Lalu Lintas Harian (LHR) adalah jumlah / volume lalu lintas yang lewat oleh beban lalu lintas pada ruas jalan dilokasi penelitian.

2. CBR dan DDT dipergunakan hanya untuk sub-grade (tanah dasar) bukan untuk subbase dengan CBR kuat tekan tergantung dari komposisi campuran, di mana CBR tinggi belum tentu menghasilkan kuat tekan yang tinggi. Tetapi jika kuat tekan tinggi, nilai CBR pun akan tinggi. Kuat tekan didapat dari hasil pengujian laboratorium.

3. Untuk membuat formula campuran sampel tanah dengan menggunakan Serbuk Styrofoam dan biji plastik jenis PVC pada komposisi 0\%, 1\%, dan 1,5\%.

4. Penelitian mencakup pengambilan sampel tanah, pembuatan benda uji dan pengujian CBR (California Bearing Ratio).

Tempat penelitian di Jalan Poros Desa Batumarta I sampai Desa Battu Winangun Kecamatan Lubuk Raja Kabupaten Ogan Komering Ulu. Panjang jalan yang diteliti adalah $\pm 2 \mathrm{~km}$ terbagi menjadi 500 meter. Dan sampel diambil yang berjumlah 3 titik 


\section{HASIL DAN PEMBAHASAN}

Lokasi jalan bertempat di Jalan Poros Desa Batumarta I sampai Desa Battu Winangun Kecamatan Lubuk Raja Kabupaten Ogan Komering Ulu sepanjang $\pm 2 \mathrm{~km}$ yang menghubungkan dari Jalan Poros Desa Batumarta I sampai ke Desa Battu Winangun, di mana kondisinya terdapat kerusakan di berbagai titik. Dan badan ruas jalan tersebut dilalui kendaraan bermotor, mobil ringan, bus dan truk. Kendaraan muatan dengan ukuran lebar tidak melebihi 2,50 m, ukuran panjang maksimal $18 \mathrm{~m}$ muatan dan sumbu terberat yang diijinkan 10 ton. Data lalu lintas harian (LHR) tahun $2021=12.341 / 7=1637$ kendaraan $/$ hari. Dalam penelitian ini untuk sampel tanah di ambil pada lokasi ruas jalan Poros Desa Batumarta I sampai Desa Battu Winangun Kecamatan Lubuk Raja Kabupaten Ogan Komering Ulu. Penelitian dimulai dengan pengambilan tanah dengan hand bor dengan kedalaman $60 \mathrm{~cm}$ dan $80 \mathrm{~cm}$ dari setiap titik pengeboran. Dan dilakukan sebanyak 3 titik pengeboran. Tujuannya adalah untuk mengetahui nilai CBR tanah dasar (subgrade). Pemeriksaan nilai CBR menggunakan CBR metode laboratorium yaitu pemeriksaan langsung pada contoh tanah asli tanpa perendaman. Uji coba dilakukan di laboratorium Fakultas Teknik Program Studi Teknik Sipil Universitas Baturaja, dengan hasil data seperti dinyatakan dalam tabel-tabel dan gambar berikut :

Tabel 3. Hasil nilai CBR tanah dasar sebelum dan sesudah di campur serbuk styrofoam dan biji plastik pada titik sampel 1

\begin{tabular}{clcc}
\hline No & Tanah dasar + serbuk Styrofoam dan biji plastik & $\begin{array}{c}\text { Hasil Nilai } \\
\text { CBR }\end{array}$ & $\begin{array}{c}\text { Kualitas Uji } \\
\text { CBR }\end{array}$ \\
\hline 1 & Tanah dasar & 5,8 & Buruk \\
2 & Tanah dasar + serbuk Styrofoam dan biji plastik 1\% & 6,0 & Buruk \\
3 & Tanah dasar + serbuk Styrofoam dan biji plastik & 5,3 & Buruk \\
& $1,5 \%$ & & \\
\hline
\end{tabular}

Tabel 4. Hasil nilai CBR tanah dasar sebelum dan sesudah di campur serbuk styrofoam dan biji plastik pada titik sampel 2

\begin{tabular}{clcc}
\hline No & Tanah dasar + serbuk Styrofoam dan biji plastik & $\begin{array}{c}\text { Hasil Nilai } \\
\text { CBR }\end{array}$ & $\begin{array}{c}\text { Kualitas Uji } \\
\text { CBR }\end{array}$ \\
\hline 1 & Tanah dasar & 5,6 & Buruk \\
2 & Tanah dasar + serbuk Styrofoam dan biji plastik 1\% & 5,9 & Buruk \\
3 & Tanah dasar + serbuk Styrofoam dan biji plastik & 4,8 & Buruk \\
& & & \\
\hline
\end{tabular}

Tabel 5. Hasil nilai CBR tanah dasar sebelum dan sesudah di campur serbuk styrofoam dan biji plastik pada titik sampel 3

\begin{tabular}{clcc}
\hline No & Tanah dasar + serbuk Styrofoam dan biji plastik & $\begin{array}{c}\text { Hasil Nilai } \\
\text { CBR }\end{array}$ & $\begin{array}{c}\text { Kualitas Uji } \\
\text { CBR }\end{array}$ \\
\hline 1 & Tanah dasar & 4,7 & Buruk \\
2 & Tanah dasar + serbuk Styrofoam dan biji plastik 1\% & 5,2 & Buruk \\
3 & Tanah dasar + serbuk Styrofoam dan biji plastik & 4,1 & Buruk \\
& $1,5 \%$ & & \\
\hline
\end{tabular}


Tabel 6. Peningkatan hasil keseluruhan Nilai CBR terhadap campuran serbuk styrofoam dan biji plastik

\begin{tabular}{|c|c|c|c|c|}
\hline \multirow{2}{*}{ No } & \multirow{2}{*}{ Komposisi Campuran } & \multicolumn{3}{|c|}{ Titik Sample } \\
\hline & & 1 & 2 & 3 \\
\hline 1 & Tanah dasar & 5,8 & 5,6 & 4,7 \\
\hline 2 & $\begin{array}{l}\text { Tanah dasar + serbuk styrofoam dan biji plastik } \\
1 \%\end{array}$ & 6.0 & 5,9 & 5,2 \\
\hline 3 & $\begin{array}{l}\text { Tanah dasar + serbuk styrofoam dan biji plastik } \\
1,5 \%\end{array}$ & 5,3 & 4,8 & 4,1 \\
\hline
\end{tabular}

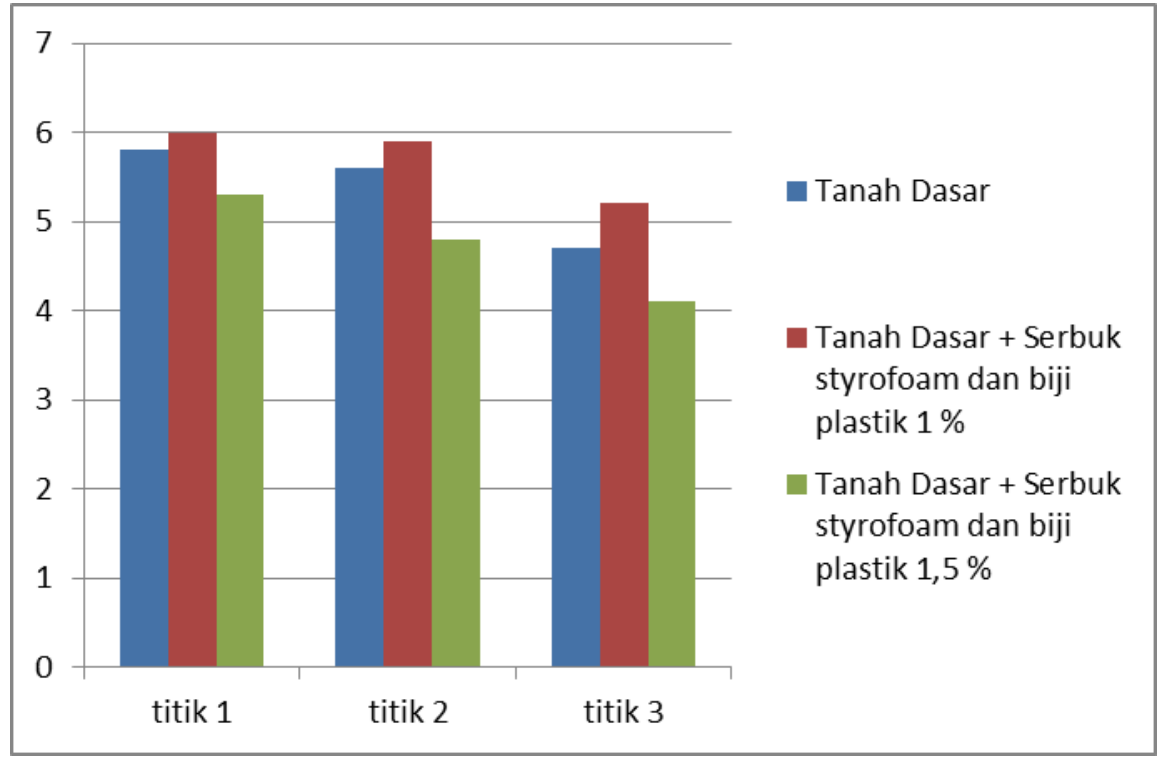

Gambar 3. Grafik Peningkatan Nilai CBR Tanah Dasar

Dengan Campuran Styrofoam dan Biji Plastik

Dari gambar 3 diatas nilai CBR titik sampel 1 yang tertinggi terjadi pada kondisi tanah dasar yang ditambah serbuk styrofoam dan biji plastik 1\% dengan nilai 6,0 (DDT 52) dan menurun pada kondisi penambahan serbuk styrofoam dan biji plastik $1,5 \%$ dengan nilai 5,3. Demikian juga pada titik sampel 2 dengan nilai 5,9 dan 4,8, juga pada titik sampel 3 dengan nilai 5,2 dan 4,1

\section{KESIMPULAN}

Berdasarkan survey dilapangan ruas Jalan Poros Desa Batumarta I sampai Desa Battu Winangun Kecamatan Lubuk Raja Kabupaten Ogan Komering Ulu dan penelitian di Laboratorium Fakultas Teknik Program Studi Teknik Sipil Universitas Baturaja, dapat di simpulkan bahwa hasil penelitian pengaruh penambahan serbuk Styrofoam dan biji plastik terhadap nilai CBR pada tanah dasar sebagai berikut :

a. Nilai CBR dengan penambahan campuran serbuk styrofoam dan biji plastik pada komposisi campuran komposisi $1 \%$ dapat meningkatkan nilai CBR dan nilai DDT dengan korelasi yang cukup yaitu di titik 1 CBR 6,0 \% - 52 DDT, titik 3 CBR 5,2 \% 4,8 DDT, sedangkan di titik 2 CBR 5,9\% - 5,1 DDT.

b. Nilai CBR di titik 3 tidak mencapai nilai kualitas CBR yang maksimal. 
c. Komposisi campuran tanah dasar ditambah $1 \%$ serbuk styrofoam dan biji plastik merupakan formula komposisi campuran yang baik dan dapat mencapai nilai CBR yang stabil terutama di titik 1 dan titik 2 .

d. Semakin besar kadar serbuk styrofoam dan biji plastik yang ditambahkan, maka daya dukung tanah akan mengalami penurunan di karenakan serbuk styrofoam dan biji plastik merupakan unsur material bukan pengikat.

Disarankan untuk penelitian selanjutnya perlu ditambahkan lagi variasi campuran yang lebih baik sehingga dapat mencapai hasil nilai CBR yang maksimal, karena styrofoam dan biji plastik tidak terlalu meningkatkan nilai CBR tanah asli secara signifikan.

\section{DAFTAR PUSTAKA}

Bowles, J. E., 1991, Analisa dan Desain Pondasi, Edisi keempat Jilid 1, Erlangga, Jakarta.

Gunarti, A. S. S. (2013). Atterberg Limit pada Tanah Lempung yang distabilisasi dengan Natrium Karbonat. Bentang: Jurnal Teoritis dan Terapan Bidang Rekayasa Sipil, 1(2), 15-21.

Lindawati, L., \& Sari, E. K. (2019). Analisa Pengaruh Penambahan Limbah Gypsum Terhadap Nilai CBR Tanah Dasar di Ruas Jalan BK 1 Desa Tanjung Bulan Kabupaten OKU Timur. Jurnal Deformasi, 4(1), 13-20.

Norhadi, A., Fauzi, M., \& Rukmana, M. Y. I. (2017). Penentuan Nilai CBR dan Nilai Penyusutan Tanah Timbunan (Shrinkage Limit) Daerah Barito Kuala. Poros Teknik, 9(1), 1-6.

Purwanto, H., Adiguna, A., Rustam, R. K., \& Budiarto, B. A. (2020). Pemanfaatan Minyak Mentah (Crude Oil) untuk Meningkatkan Stabilisasi Jalan Tanah pada Daerah Makarti Jaya Kabupaten Banyuasin. Jurnal Deformasi, 4(2), 64-72.

Purwanto, H., Setiobudi, A., \& Rustam, R. K. (2020). Stabilization of soft clay soil using a gypsum plafond waste based on CBR testing. Int. J. Sci. Technol. Res, 9(2), 963968.

Rustam, R.K (2018, November). Studi Sifat Mekanis Tanah Merah dengan Pengujian Triaksial. In Jurnal Forum Mekanika (Vol. 7, No. 1, pp. 29-34).

Rustam, R. K., Purwanto, H., Adiguna, A., \& Putri, I. T. (2020). Pengaruh Penambahan Abu Arang Tempurung Kelapa Terhadap Kuat Geser Tanah Lempung di Daerah Makarti Jaya. Jurnal Deformasi, 4(2), 86-95.

Setiawan, D., Afriani, L., \& Setyanto, S. (2016). Studi Dan Analisa Campuran Tanah Lempung Dan Abu Sekam Padi Terhadap Nilai Permeabilitas Dengan Alat Falling Head. Jurnal Rekayasa Sipil dan Desain, 3(3), 493-506.

Simanjuntak, M. R. A., Lubis, K., \& Rangkuti, N. M. (2017). Stabilisasi Tanah Lempung dengan Campuran Pasir Pantai terhadap Nilai CBR. JCEBT (Journal of Civil Engineering, Building and Transportation), 1(2), 96-104. 
Susmarani, M. (2012). Studi Daya Dukung Tanah Lempung Lunak yang Distabilisasi Menggunakan TX-300 Sebagai Lapisan Subgrade. Skripsi, Universitas Lampung, Lampung.

Watie, J. S., \& Chandra, A. A. (2021). Pengaruh Penambahan Semen Dan Kapur Terhadap Stabilisasi Tanah Merah Distrik Mindiptana Kabupaten Boven Digoel. CRANE: Civil Engineering Research Journal, 2(1), 12-17. 